Hoor, somewhat dazed, but soon recovered consciousness. Mr. Carlyon, of Redruth, was immediately sent for. The man stated to him that he stood before the looking glass, and turning his head well round to the left, placed the muzzle of the revolver behind his right ear. He then fired and was aware of the fact that the bullet fell out of his mouth on to the dressing table. It was subsequently found by $\mathrm{Mr}$. Carlyon on the floor of the room.

On examination it was discovered that he had shot himself through the right mastoid process; the wound of exit into the mouth was conjectured to be somewhere behind the soft palate. There was some considerable hæmorrhage both from the wound and also from the mouth.

On December 5th I saw this case in consultation with Mr. Carlyon. He was in bed, perfectly collected and apparently suffering but little distress, except from a somewhat troublesome cough, accompanied with blood-stained muco-purulent expectoration. His breathing was natural, his lungs were not affected, and he could swallow with but little pain. His tongue, which was very much coated was, on protrusion, strongly deflected to the right side. His sight was normal in both eyes, and his pupils active. He was a little deaf in his right ear. His upper extremities were not affected; but on getting him out of bed I found that he slightly dragged his right leg. His patellar reflex on that side was diminished, and on tickling the bottom of his right foot there was no response. Sensation was normal. On lifting the soft palate I found the wound of exit at the back of the pharynx, a little to the right of the median line, and surrounded with extensive ecchymosis. His temperature was $99.2^{\circ}$ (having been subnormal the night before), and his pulse 123 .

From this date Mr. Carlyon tells me he rapidly became worse. His temperature and pulse rose daily, and on the day of his death his temperature was $102.6^{\circ}$, and his pulse 163 .

On December 4 th he was attacked with acute congestion of his right lung. The deafness in the right ear increased. I append two drawings, one illustrating the original size and shape of the bullet, and the other the condition in which it was found. In the interstices of the lead a quantity of bony tissue was deposited. Infortunately, no post-mortem examination could he ohtained.

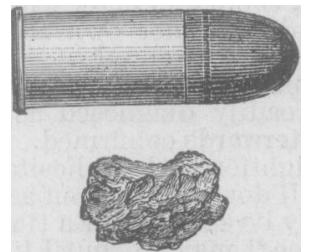

The probable course of the bullet was as follows:--Penetrating obliquely the posterior surface of the mastoid, it just missed the lateral sinus and, without entering the skull, it then passed between the jugular fossa and right condyle of the occipital bone, cutting the hypoglossal nerve at the anterior condyloid foramen, and injuring the pneumogastric and glosso-pharyngeal as they emerge from the anterior part of the jugular fossa. It then made its way forward under the basilar process of the occipital, emerging through the posterior wall of the pharynx, and probably in so doing bruised the upper part of the spinal cord on the right side, which would be somewhat exposed to injury by flexion and rotation of the head to the left.

Such a course and the injuries inflicted would account for the various symptoms noticed.

\section{ON THE PREVENTION OF INFAN'TILE OPH'THALMIA.}

BY KARL (iROSSMANN, M.D., F.R.C.S.E., Ophthalmic Surgeon, Stanley Hospital, Liverpool.

If I were to discuss the treatment and the prevention of blenorrhoea neonatorum, I should have to repeat almost word for word what I said last year before the annual meeting at Leeds ; and it will be less tiring and more expedient to dis-

${ }^{1}$ head in the Sect'rn of Ophthalmology at the Annual Meeting of the British Medic Association, held in Birmingham, Julv, 1890. tribute a reprint of my paper read on that occasion, and to make a sort of addendum to it. Not that our knowledge of the disease has undergone any great modification. That was scarcely possible, since its etiology and pathology are familiar enough to us all. Neither was there any urgent need to add to the remedies by which it may be treated. We have already a sufficient number at our disposal; and although we shall always be glad to add to our armamentarium such new names as pyoktanin, we need not forget that what we have had hitherto has proved itself thoroughly efficient.

The reason why I recur to this subject to-day is twofold. First, it is our duty to strive to prevent disease. The individual can do something to this end; but individual efforts are limited; and, to secure substantial results, combination will be needed and State enforcements of precautions. We know how the efforts of the Committee of the Ophthalmological Society on this subject collapsed, because the resolutions which were put forward were not adopted in proper quarters; and the matter ended there. Distribution of cards may have been very good as far as it went, but, even if carried out, would probably have fallen short of the desired effect.

The possibility of the prophylaxis of the disease rests chiefly with midwives, because confinements in those classes which yield the largest percentage of blindness from this cause, are principally attended by midwives and not by medical practitioners. It is, therefore, through the instrumentality of midwives that we must hope to banish this scourge. The present time is very favourable for considering what steps ought to be taken. Of course, legislation only can help here. In Saxony, where Professor Crédé was the first to point out and to prove by thousands of cases the possibility of effectually preventing infantile ophthalmia, the regulations for midwives treat fully on the matter. As far back as 1882 regulations were made and were further amplified in 1885. In Prussia less stringent rules exist, but the midwives are fully instructed as to the danger of the disease, and are directed what to do.

It was therefore a great satisfaction to me to see that quite recently the State of New York has legislated on the matter. Through the kindness of Dr. Swann Burnett, of Washington, who was with us last year at Leeds (and who personally has been instrumental in bringing about this law), I am enabled to give its text. It is short and decided, and runs thus:

"Section I. Should any midwife or nurse having charge of an infant in this State notice that one or both eyes of such infant are inflamed or reddened at any time within two weeks after its birth, it shall be the duty of such midwife or nurse so having charge of such infant to report the fact in writing within six hours to the health officer or some legally qualified practitioner of medicine of the city, town, or district in which the parents of the infant reside.

"Section II. Any failure to comply with the provisions of this Act shall be punished by a fine not to exceed one hundred dollars, or imprisonment not to exceed six months, or both.

"Section III. This Act shall take effect on the first of September, eighteen hundred and ninety."

Here, then, is a step in the right direction. I think it is all the more necessary for us to take some steps, as a Bill was recently brought before Parliament concerning midwives, and, though shelved for six months, is likely to be heard of again.

\section{BLEPHAROCHEILOPLASTIC OPERA'TIONS.}

BY ARTHLR BENSON, F.R.C.S.I.

Issistant-Surgeon, St. Nark's Ophthalmic Hospital, Dublin.

Two years ago I brought before the Ophthalmological section of the British Medical Association (Glasgow meeting) the subject of entropion and trichiasis, with special reference to the operative measures for their cure. I would not again venture to bring the subject forward in any form but that I have received so many letter's from different ophthalmic surgeons asking for further information regarding the operation of transplanting mucous membrane from the mouth to the eyelids.

1 Read in the Section of Ophthalmology at the Annual Meeting of the British Medical Association held in Birmingham, July, 19:\%. 